\title{
Rapid screening for bacterial phenotypes capable of biodegrading anionic surfactants: development and validation of a microtitre plate method
}

\author{
Corby Lee, $†$ Nicholas J. Russell and Graham F. White
}

Author for correspondence: Graham F. White. Tel: +441222 874188. Fax: +44 1222874116.
e-mail: whitegf1@,cardiff.ac.uk

School of Molecular and Medical Biosciences,

Biochemistry Unit, University of Wales Cardiff, PO Box 911, Cardiff CF1 3US, Wales, UK

\begin{abstract}
The Biolog microtitre plate assay, which is based on tetrazolium dye reduction as an indicator of sole-carbon-source utilization, has been evaluated as a rapid method to investigate the biodegradation of five classes of anionic surfactant by pure and mixed cultures of bacteria. The assay gave reproducible results over a fourfold range of inoculum optical density, and the surfactant concentration was selected to provide a compromise between the length of the lag period prior to colour production and the maximum colour produced. A kinetic model was developed and used to analyse the appearance of colour in the assay and was found to give rise to three biologically significant parameters describing the processes underlying the assay. No false-positives were obtained with environmental isolates. The small number of falsenegatives obtained ( $<8 \%$ of the total) could be explained by the methodology used to prepare the bacterial inoculum. All isolates which were positive in the Biolog assay were shown to be both primary and ultimate degraders of the test surfactant. These results show that the method provides a useful means of studying the biodegradation of anionic surfactants by both pure and mixed cultures of bacteria and will find use in the rapid analysis of biodegradation kinetics and specificities of larger numbers of individual isolates than hitherto possible. In addition, an important benefit of the methodology is that it can be used for direct analysis of the biodegradation potential of whole bacterial communities without having to make an artificial selection during laboratory growth.
\end{abstract}

Keywords: Biolog assay, microtitre plate, screening bacteria, surfactant biodegradation

\section{INTRODUCTION}

World production of synthetic surfactants in 1991 was 7 million metric tons, of which 1.8 million metric tons were anionic surfactants (Hauthal, 1992). Irrespective of their initial usage, the vast majority of these surfactants eventually reach waterways, either directly or via domestic sewage treatment works, in which microbial populations are responsible for their biodegradation.

\footnotetext{
†Present address: Abacus Water Treatment Ltd., 14/15 Ladford Covert, Seighford, Stafford ST18 90G, UK.

Abbreviations: AES, alkyl ethoxy sulphate; LABS, linear alkyl benzene sulphonate; MBAS, methylene-blue-active substance; PANS, primary alkane sulphonate; PLAS, primary linear alkyl sulphate; SLAS, secondary linear alkyl sulphate; SNS, sodium nonyl sulphate.
}

Previous methods used to study the microbial biodegradation of anionic surfactants include isolation and characterization of the enzymes involved (Bateman et al., 1986; Cloves et al., 1980; Shaw et al., 1980) and the analysis of biodegradation kinetics in shake-flask die-away experiments (Anderson et al., 1990) in which surfactant is exposed to micro-organisms in a closed system and its disappearance monitored over time. While these methods can provide useful indications of the biodegradative capacity of pure and mixed bacterial cultures, each is limited by the complexity of the procedures which renders them useless for large-scale screening of the indigenous microflora responsible for anionic surfactant biodegradation.

The work of Bochner \& Savageau (1977) showed that tetrazolium dye reduction could be used as a generalized 
indicator of sole-carbon-source utilization. This principle was applied subsequently to produce a commercially available microtitre plate-based assay, the Biolog MT plate (Bochner, 1989a, b). The assay is performed in a standard 96-well microtitre plate, each well of which contains the necessary redox chemicals, buffers and nutrients in a dried film. The procedure (Biolog Inc., 1993) requires the addition of the test carbon source followed by inoculation with the test organism. Mineralization of the test substrates gives rise to an increase in reducing equivalents in the bacteria which in turn irreversibly reduce the Tetrazolium Violet dye giving rise to the purple colour characteristic of a positive Biolog assay. The principal advantage of this assay over conventional techniques is the ability to assay many organisms and/or carbon sources using a single microtitre plate. For example, this was exploited by Garland \& Mills (1991) in their use of Biolog plates containing 95 different carbon sources (viz. the commercially available Biolog GN microtitre plate) to classify and characterize whole microbial communities on the basis of their patterns of solecarbon-source utilization.

Whilst the Biolog MT plate is a relatively new tool for use in biodegradation studies, its use is increasing. It has been used to screen bacteria from such diverse environments as Kraft-pulp effluent-treatment plants (Victorio et al., 1993a, b) and terrestrial sub-surface sites (Lee et al., 1992), for their biodegradative abilities towards a wide variety of compounds, including chlorinated aromatics (Victorio et al., 1993a, b), isocyanate-based biodegradable polymers (Odocha et al., 1994) and a range of volatile and nonvolatile toxic organic compounds (Strong-Gunderson et al., 1992; Gordon et al., 1993). While all these authors have obtained meaningful results utilizing Biolog MT plates, none has validated the data obtained with the Biolog assay against more traditional methods.

In this paper we report the development of the Biolog MT plate assay to screen pure and mixed bacterial cultures for their ability to biodegrade five classes of sulphated and sulphonated anionic surfactants. The results of this application have been validated against accepted methods of assaying both primary and ultimate biodegradation of such compounds.

\section{METHODS}

Materials. Biolog MT Microplates were purchased from Biolog Inc. (Hayward, CA 94545, USA) and stored at $4{ }^{\circ} \mathrm{C}$. Bactopeptone and Casamino Acids for use in medium $M$ were obtained from Difco. Methylene Blue vital stain grade C.I. 52015 for use in the methylene-blue-active substance (MBAS) assay was purchased from Merck. Ultrapure water for preparation of all assay solutions was obtained by passing glassdistilled water through a Millipore Milli-Q50 unit to give $18 \mathrm{M} \Omega$ resistivity water.

The following examples of five classes of anionic surfactant were used in this study. SDS specially purified for biochemical work (Merck) and sodium nonyl sulphate (SNS; Lancaster Synthesis Ltd) were selected as representative primary linear alkyl sulphates (PLAS). Potassium undecan-2-yl sulphate, a secondary linear alkyl sulphate (SLAS), was synthesized by the method of White et al. (1980) and shown to be $>99 \%$ pure (determined by ${ }^{1} \mathrm{H}$ - and ${ }^{13} \mathrm{C}-\mathrm{NMR}$ ). The primary alkane sulphonate (PANS) sodium 1-dodecane sulphonate was purchased from Lancaster Synthesis Ltd. A commercial alkyl ethoxysulphates (AES) formulation, Empicol ESB70, containing approximately $70 \%(\mathrm{w} / \mathrm{w})$ alkyl ethoxy sulphates (with alkyl chain lengths from $\mathrm{C}_{10}$ to $\mathrm{C}_{14}$ with mainly two ethoxy units), $3.5 \%$ unsulphated alcohol ethoxylate, $1.5 \%$ sodium sulphate, $0.3 \%$ sodium chloride and the balance as water, was donated by Albright and Wilson. A commercial formulation of linear alkylbenzene sulphonates (LABS), NANSA HS80/S, containing approximately $80 \%(\mathrm{w} / \mathrm{w})$ sodium dodecyl benzene sulphonate), $1.7 \%$ unsulphonated dodecylbenzene, $3.8 \%$ sodium tripolyphosphate, $12 \%$ sodium sulphate and the balance as water, was also donated by Albright and Wilson. The commercial mixtures (AES and LABS) were deliberately included despite their non-surfactant impurities, to show that the method is equally valid for both pure surfactant components and commercial formulations. The important feature about the composition of the commercial materials is that they contain minimal amounts of non-surfactant organic material which would otherwise influence respiration activity in the Biolog plates. All other chemicals were of analytical grade supplied by Merck or Fisons Scientific.

Culture media. Medium $\mathrm{M}$, an agar-containing non-selective growth medium based on the casein-peptone-starch (CPS) medium of Jones (1970) and supplemented with glycerol (Burton et al., 1982), was used for the growth of environmental isolates. Liquid medium $\mathrm{M}$ was obtained by omitting agar and supplementing with $0.2 \%(\mathrm{w} / \mathrm{v})$ bacto-peptone. In some experiments when screening environmental isolates for their surfactant-degrading capabilities, medium $\mathrm{M}$ was supplemented with a mixture of surfactants.

Minimal medium for the isolation and growth of bacteria with surfactant as the sole carbon source had the following composition $\left(1^{-1}\right): \mathrm{K}_{2} \mathrm{HPO}_{4}, 1.5 \mathrm{~g} ; \mathrm{KH}_{2} \mathrm{PO}_{4}, 3 \mathrm{~g} ; \mathrm{NH}_{4} \mathrm{Cl}, 0.5 \mathrm{~g}$; $\mathrm{NaCl}, 0.5 \mathrm{~g} ; \mathrm{MgCl}_{2} .6 \mathrm{H}_{2} \mathrm{O}, 0.15 \mathrm{~g} ; \mathrm{Na}_{2} \mathrm{SO}_{4}, 0.14 \mathrm{~g}$; trace elements solution, $1 \mathrm{ml}$. When required, the medium was solidified with $15 \mathrm{~g}$ Type 1-A Agarose (Sigma). This base medium was sterilized by autoclaving at $121^{\circ} \mathrm{C}$ for $20 \mathrm{~min}$, cooled to $50^{\circ} \mathrm{C}$ and amended with one of the following filtersterilized surfactants at the indicated final concentrations: PLAS, $4 \mathrm{mM}$ SNS; AES, $3 \mathrm{mM}$ Empicol ESB70; SLAS, $3.5 \mathrm{mM}$ potassium undecan-2-yl sulphate; PANS, $3.5 \mathrm{mM}$ sodium 1-dodecane sulphonate; LABS, $3 \mathrm{mM}$ NANSA HS80/S. Concentrations of Empicol ESB70 and NANSA HS80/S are stated as molar concentrations of the pure surfactant calculated using the manufacturer's data for mean molecular mass and percentage purity.

Bacterial strains. Escherichia coli strain JM101 (ATCC 33876, NCIMB 11926) was used as a representative non-surfactantdegrading organism and maintained on nutrient agar. Pseudomonas C12B (ATCC 43648, NCIMB 11753), originally isolated for its ability to mineralize SDS (Payne \& Feisal, 1963) and recently identified as Ps. aeruginosa (unpublished results), was used as the known degrading organism for PLAS. Organisms capable of growth on the four other classes of surfactant were obtained by standard enrichment techniques using activated sludge as the inoculum. Single, pure isolates were obtained for AES, SLAS and PANS, and these were maintained by twice-weekly subculture on solid minimal medium containing the respective surfactant as sole carbon source. A four-membered consortium capable of mineralizing LABS was obtained, no single member of which was able to grow on solid medium containing NANSA HS80/S as the sole carbon source. This consortium was maintained by twiceweekly subculture in fresh liquid minimal medium containing 
$0.25 \%(\mathrm{w} / \mathrm{v}$ ) NANSA HS80/S. Long-term stocks of pure isolates and the LABS-degrading consortium were stored frozen on glass beads at $-70^{\circ} \mathrm{C}$ (Jones et al., 1991).

Surfactant die-away test. Aliquots $(76 \mathrm{ml})$ of autoclaved liquid minimal medium in $250 \mathrm{ml}$ Erlenmeyer flasks were amended with filter-sterilized surfactant to give a final concentration of $80 \mu \mathrm{M}$. An inoculum was added and the flasks were incubated at $30{ }^{\circ} \mathrm{C}$ in a gyratory incubator at 150 r.p.m. At intervals, $2 \mathrm{ml}$ samples were removed and frozen at $-20^{\circ} \mathrm{C}$ for later assay of MBAS.

Small-scale die-aways were performed in sterile, capped, polystyrene test-tubes $(100 \mathrm{~mm} \times 18 \mathrm{~mm})$ containing $5 \mathrm{ml}$ medium. Samples $(1 \mathrm{ml})$ were removed at the beginning and end of the die-away and frozen at $-20^{\circ} \mathrm{C}$ for later MBAS assay to determine the total loss of MBAS during the die-away.

MBAS assay. The method used was essentially that of Hayashi (1975), as modified by Thomas (1987). Assays were performed in nitric-acid-washed, optically matched test tubes. Results were calculated as percentage loss of original MBAS.

Biolog methodology. The manufacturer's standard methodology is as follows (Biolog Inc., 1993). (a) Grow bacteria on a non-selective solid medium. (b) Prepare, within the standardized OD range, a uniform suspension of cells in sterile, normal $(0.85 \% \mathrm{w} / \mathrm{v})$ saline. (c) Add test substrate to each well in a volume of $15 \mu \mathrm{l}$. (d) Inoculate the cell suspension $(135 \mu \mathrm{l}$ per well) into the Biolog plate. (e) Incubate the plate under appropriate conditions. ( $\mathrm{f}$ ) Analyse the colorimetric changes by eye or by measurement of $A_{590}$.

This standard methodology was modified for use in the present study as follows. (a) Our experience has shown that many bacteria isolated during studies of surfactant biodegradation grow into solid media forming effuse colonies, making their subsequent removal for resuspension difficult. Therefore, the isolates in this study were grown to the mid-exponential phase of growth in liquid medium in shake-flasks at $30^{\circ} \mathrm{C}$. Bacteria were harvested by centrifugation at $3000 \mathrm{~g}_{\mathrm{av}}$ for $10 \mathrm{~min}$ and washed in $0.85 \% \mathrm{NaCl}$ in $10 \mathrm{mM}$ sodium phosphate buffer, $\mathrm{pH} 7 \cdot 2$. All solutions were maintained at $30^{\circ} \mathrm{C}$ to avoid coldshocking the bacteria. Centrifugation and washing were repeated twice. (b) The final bacterial pellet was resuspended in PBS and the absorbance of the resultant bacterial suspension adjusted to give an $A_{590}$ value of approximately 0.4 using a Novaspec II spectrophotometer (LKB Pharmacia) measuring against a PBS blank. This value corresponds to approximately $5 \times 10^{8}$ bacteria $\mathrm{ml}^{-1}$. (c) Test surfactants were dissolved in

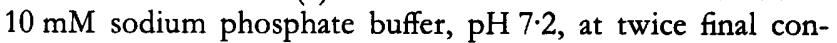
centration, and $75 \mu \mathrm{l}$ added per well. To correct for endogenous respiration and the carry-over of carbon from the bacterial cultures, corresponding blank wells (i.e. containing no test surfactant) were prepared containing $75 \mu \mathrm{l} 10 \mathrm{mM}$ sodium phosphate buffer, $\mathrm{pH} 7 \cdot 2$. (d) The standardized bacterial suspension was added to the plate $(75 \mu$ l per well). (e) The plate was incubated at $30^{\circ} \mathrm{C}$ without agitation. ( $f$ ) To correct for the interference arising from the absorbance of bacteria and any precipitates formed in the wells, the plates were read in an Anthos 2001 microtitre plate reader (Denley Instruments), under computer control, using a measurement wavelength of $590 \mathrm{~nm}$ and a reference wavelength of $650 \mathrm{~nm}$. The results produced by the plate reader were in the form of $A_{590}-A_{650}$ which represents the true purple/blue colour produced as a positive result in the Biolog assay. The resultant absorbances were used to calculate the net Biolog colour which was defined as follows:

Biolog colour $=$

$$
\left[\left(A_{590}-A_{650}\right)_{\text {test well }}-\left(A_{590}-A_{650}\right)_{\text {blank well }}\right] \times 1000
$$

Thus Biolog colour represents the net increase in absorbance produced by metabolism of the added test surfactant.

The time-dependent changes in Biolog colour were calculated by subtraction of the time zero value. Positive values of Biolog colour represented biodegradation of the test surfactant, i.e. the colour in the test well exceeded that in the blank well due to an increase in respiration as a result of biodegradation of the test surfactant. A value of zero represented no biodegradation of test surfactant. It was assumed that a negative value meant that the test surfactant was inhibitory to the test isolate, so the level of endogenous respiration in the blank well exceeded that of the test well, giving rise to more colour in the blank well than in the test well.

\section{RESULTS}

\section{Kinetic modelling of Biolog colour production}

Tests were carried out with three versions of a logistic kinetic model, i.e. one where an initially growthaccelerated increase in the colour production becomes limited by exhaustion of a substrate. Two of these models were four-parameter and five-parameter models included in the non-linear regression package (SigmaPlot for Windows V1.02 from Jandel Scientific) used to curve-fit the data, and the third was a modification of the logistic growth curve proposed by Zwietering et al. (1990). The data were found to be modelled most accurately by the Zwietering equation which has the added advantages that its parameters are fewer in number (three) and they also have biological relevance. This model describes the Biolog colour, $A$, developed at time, $t$, as:

$$
A=\frac{A_{\max }}{\left\{1+\exp \left[\frac{4 \mu_{m}}{A_{\max }}(\lambda-t)+2\right]\right\}}
$$

This kinetic model gives rise to three biologically

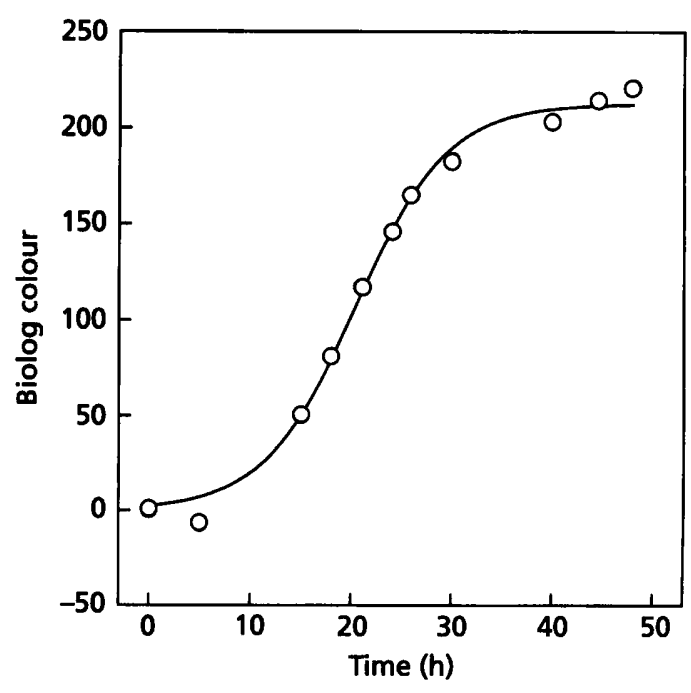

Fig. 1. The kinetics of colour appearance in the PLAS Biolog assay of Pseudomonas C12B grown on medium $M$ containing $1 \mathrm{mM}$ SNS. The solid line is the line of best fit arising from the non-linear regression fitting of the logistic kinetic model to the experimental data (O). 

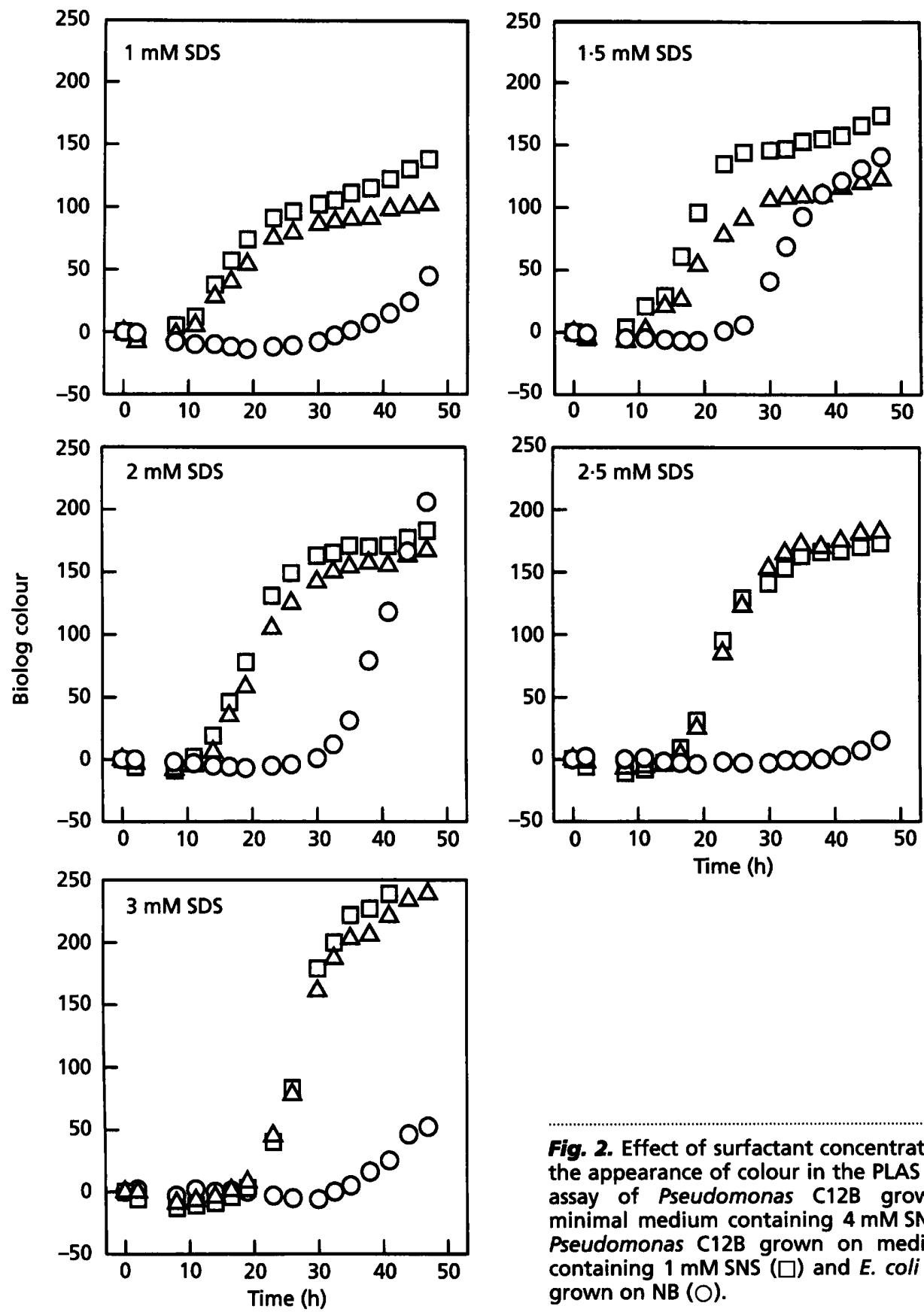

Fig. 2. Effect of surfactant concentration on the appearance of colour in the PLAS Biolog assay of Pseudomonas C12B grown on minimal medium containing $4 \mathrm{mM}$ SNS $(\triangle)$, Pseudomonas C12B grown on medium $M$ containing $1 \mathrm{mM}$ SNS $(\square)$ and $E$. coli JM101 grown on NB (O).

significant parameters: $A_{\max }$, the asymptote or maximum colour produced; $\mu_{m}$, the maximum rate of colour production; and $\lambda$, the lag period prior to the rapid production of colour. Fig. 1 illustrates the application of a curve-fitted line for one set of data arising from Pseudomonas $\mathrm{C} 12 \mathrm{~B}$ grown on medium $\mathrm{M}$ containing $1 \mathrm{mM}$ SNS, to give an inoculum $A_{590}$ value of $0 \cdot 4$, and assayed with $2.5 \mathrm{mM}$ SDS over a time-course of $48 \mathrm{~h}$. The estimates of the parameters arising from the curve-fitting process for these data were as follows: $A_{\max }, 212 \cdot 49 ; \mu_{m}$, $11.65 \mathrm{~h}^{-1} ; \lambda, 11.24 \mathrm{~h}$. The relatively small value (408.03) for the residual sum of squares which was obtained (relative to other kinetic models which were tested), together with visual inspection of the goodness of fit, suggested that this model was an accurate representation of the kinetics of Biolog colour appearance with time.

\section{Optimization of surfactant concentration in the Biolog assay}

The manufacturer's standard methodology (Biolog Inc., 1993) recommends a test-substrate concentration of between 20 and 200 p.p.m. It was decided to optimize the concentration of each surfactant class in the assay and to observe the effect of growth of the degrading organism on either minimal medium with surfactant as sole carbon 
Table 1. Estimated kinetic parameters arising from application of the logistic kinetic model to the data in Fig. 2 , illustrating the effect of surfactant concentration on colour production in the Biolog assay

The data are presented as means tasymptotic standard errors generated by the non-linear regression process. See text for an explanation of the parameters.

\begin{tabular}{|c|c|c|c|c|}
\hline Organism & $\begin{array}{c}\text { SDS } \\
(\mathbf{m M})\end{array}$ & $\lambda(\mathrm{h})$ & $\mu_{m}\left(\mathrm{~h}^{-1}\right)$ & $A_{\max }$ \\
\hline E. coli JM101 grown on NB & $\begin{array}{l}1 \cdot 0 \\
1 \cdot 5 \\
2 \cdot 0 \\
2 \cdot 5 \\
3 \cdot 0\end{array}$ & $\begin{array}{l}39 \cdot 60 \pm 4.96 \\
26.87 \pm 0.66 \\
34.37 \pm 0.37 \\
41.32 \pm 2.02 \\
36.21 \pm 0.74\end{array}$ & $\begin{array}{r}6.04 \pm 4.54 \\
11.60 \pm 1.20 \\
18.30 \pm 1.05 \\
2.68 \pm 0.98 \\
5.89 \pm 0.88\end{array}$ & $\begin{array}{c}65 \cdot 07 \pm 115 \cdot 3 \\
133 \cdot 90 \pm 4.09 \\
228 \cdot 70 \pm 13 \cdot 09 \\
21 \cdot 06 \pm 22 \cdot 53 \\
7 \cdot 21 \pm 5 \cdot 85\end{array}$ \\
\hline Pseudomonas $\mathrm{C} 12 \mathrm{~B}$ grown on medium $\mathrm{M}+1 \mathrm{mM}$ SNS & $\begin{array}{l}1 \cdot 0 \\
1 \cdot 5 \\
2 \cdot 0 \\
2 \cdot 5 \\
3 \cdot 0\end{array}$ & $\begin{array}{r}8.56 \pm 1.47 \\
11.67 \pm 0.67 \\
13.88 \pm 0.49 \\
17.55 \pm 0.69 \\
22.15 \pm 0.63\end{array}$ & $\begin{array}{r}6 \cdot 28 \pm 0.89 \\
12.65 \pm 1 \cdot 28 \\
14 \cdot 70 \pm 1 \cdot 14 \\
16.08 \pm 1 \cdot 88 \\
21 \cdot 62 \pm 2.05\end{array}$ & $\begin{array}{l}121 \cdot 50 \pm 4 \cdot 34 \\
158 \cdot 00 \pm 2 \cdot 76 \\
172 \cdot 30 \pm 2 \cdot 42 \\
164 \cdot 40 \pm 3 \cdot 29 \\
247 \cdot 60 \pm 5 \cdot 60\end{array}$ \\
\hline Pseudomonas $\mathrm{C} 12 \mathrm{~B}$ grown on minimal medium $+4 \mathrm{mM}$ SNS & $\begin{array}{l}1 \cdot 0 \\
1 \cdot 5 \\
2 \cdot 0 \\
2 \cdot 5 \\
3 \cdot 0\end{array}$ & $\begin{array}{l}10.76 \pm 1.01 \\
13.05 \pm 0.80 \\
14.78 \pm 0.64 \\
18.31 \pm 0.52 \\
21.58 \pm 0.53\end{array}$ & $\begin{array}{r}6 \cdot 38 \pm 0 \cdot 82 \\
7 \cdot 85 \pm 0 \cdot 79 \\
12 \cdot 44 \pm 1 \cdot 14 \\
16 \cdot 52 \pm 1 \cdot 44 \\
18 \cdot 39 \pm 1 \cdot 36\end{array}$ & $\begin{array}{r}94 \cdot 32 \pm 2 \cdot 40 \\
115 \cdot 30 \pm 2 \cdot 54 \\
157 \cdot 70 \pm 2 \cdot 91 \\
174 \cdot 80 \pm 2 \cdot 60 \\
228 \cdot 30 \pm 4 \cdot 31\end{array}$ \\
\hline
\end{tabular}

Table 2. Results from screening 30 environmental isolates and 6 'marker' organisms using the Biolog assay with five classes of surfactant

An organism was deemed to show a positive result $(t)$ when the colour produced in the assay. exceeded the threshold at the nominated time-point and a negative result $(-)$ when it was below this threshold (see text for details).

\begin{tabular}{|lccccc|}
\hline Organism & PLAS & AES & SLAS & PANS & LABS \\
\hline 1 & + & - & - & - & - \\
2 & + & + & - & - & - \\
3 & - & + & - & - & - \\
4 & + & + & - & - & - \\
$5-30$ & - & - & - & - & - \\
E. coli JM101 & - & - & - & - & - \\
Pseudomonas C12B & + & + & + & - & - \\
AES degrader & + & + & - & - & - \\
SLAS degrader & + & - & + & - & - \\
PANS degrader & - & - & - & + & - \\
LABS-degrading consortium & + & + & + & - & + \\
\hline
\end{tabular}

source or on medium $M$ containing a low concentration of a surfactant. The results for PLAS are illustrated in Fig. 2. The data in Fig. 2 were fitted to our modified logistic kinetic model and the resultant parameters are shown in Table 1.

There was no significant difference between colour production for Pseudomonas C12B grown on minimal medium containing $4 \mathrm{mM}$ SNS and for Pseudomonas $\mathrm{C12B}$ grown on medium $M$ containing $1 \mathrm{mM}$ SNS. In either case, increasing the concentration of SDS increased the maximum rate of colour production $\left(\mu_{m}\right)$ and the maximum Biolog colour produced $\left(A_{\max }\right)$ but also increased the length of the lag period prior to the accelerated appearance of colour. To obtain a compromise between the length of the lag period and both the amount and rate of Biolog colour production, 2.5 mM SDS was selected as the optimum concentration for the assay. The non-degrader $E$. coli JM101 yielded much longer lag periods (Fig. 2 and Table 1) before the onset of colour production. At the selected concentration of $2.5 \mathrm{mM}$ SDS, E. coli JM101 produced the longest lag and slowest colour production observed. We attribute the falsepositive colour production in E. coli JM101 to bacterial 

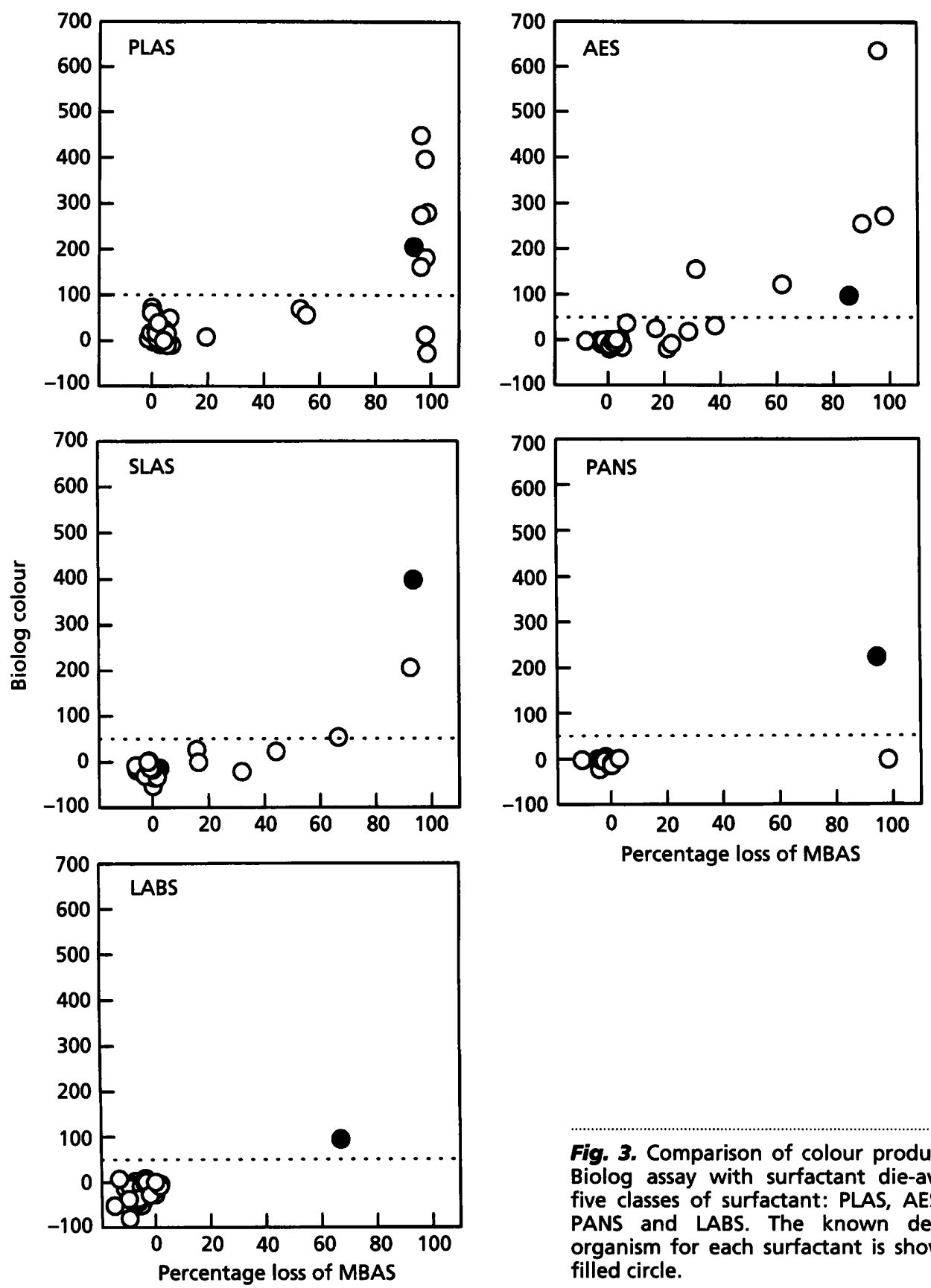

Fig. 3. Comparison of colour production in Biolog assay with surfactant die-away for five classes of surfactant: PLAS, AES, SLAS, PANS and LABS. The known degrading organism for each surfactant is shown as a filled circle.

lysis in the presence of surfactant, thus releasing carbon to increase the metabolism of the remaining intact viable cells; a concentration of $2.5 \mathrm{mM}$ SDS minimized such false-positives.

This experiment was repeated for the other classes of surfactant and similar results were obtained (data not shown). The optimum concentration for SLAS, PANS and LABS was found to be $2.5 \mathrm{mM}$ and for AES it was $2.0 \mathrm{mM}$. With the exception of LABS-containing medium, the difference in colour production for the degrading organism grown on the two different media was not significant: thus, it was decided to grow environmental isolates for Biolog assay on medium $\mathbf{M}$ amended with low concentrations of surfactant. The colour pro- duction in the LABS assay using the consortium grown on medium $\mathrm{M}$ containing $1 \mathrm{mM}$ NANSA HS80/S was low and not readily reproducible. It was necessary, therefore, to use the consortium grown on NANSA $\mathrm{HS} 80 / \mathrm{S}$ as the sole carbon source in later experiments. The other known degraders were grown on medium $M$ supplemented with the relevant surfactant.

\section{Effect of inoculum size}

The effect of inoculum size was investigated by assaying Pseudomonas $\mathrm{C} 12 \mathrm{~B}$ grown on medium $\mathrm{M}$ containing $1 \mathrm{mM}$ SNS using inocula with $A_{590}$ values of 0 (i.e. PBS only), $0.1,0.2$ and 0.4 (the Biolog recommended value) and 

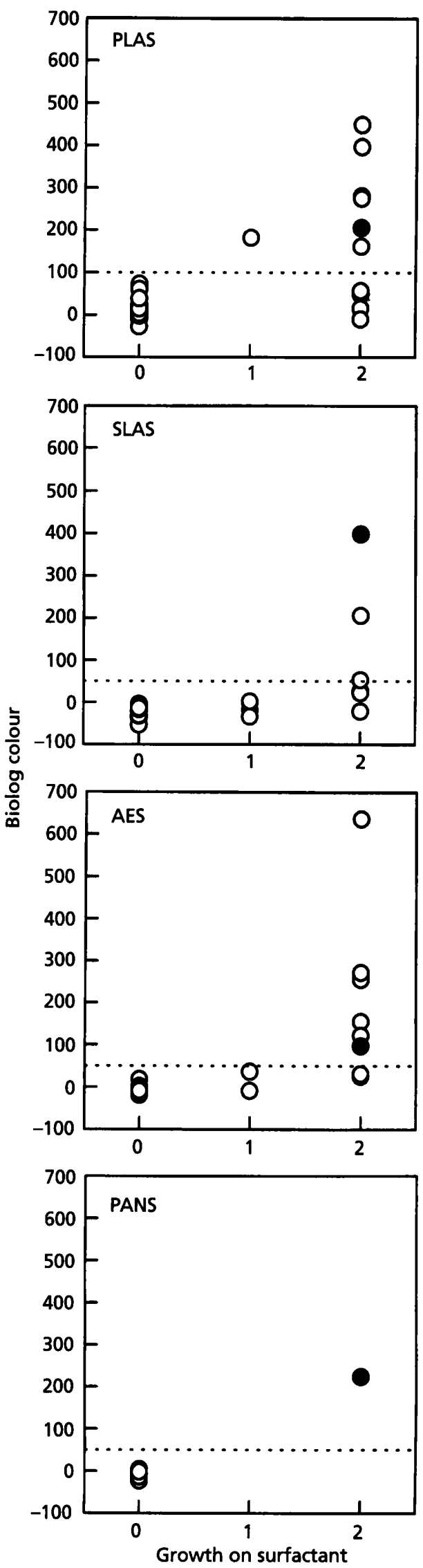

analysing the kinetics of the resultant data by application of the modified logistic model of Biolog colour appearance. Data for the PBS blank $\left(A_{590}=0\right)$ showed that no significant amount of Biolog colour was produced spontaneously without the presence of bacterial cells. On increasing the inoculum $A_{590}$ value from $0 \cdot 1$ to $0 \cdot 4$, the lag period $\lambda$ decreased from $13.07 \pm 1.12$ to $10.90 \pm 0.84$, a change of $17 \%$. The values of $\mu_{m}$ and $A_{\max }$ were constant within the standard errors. These relatively small changes in the kinetic parameters arising from a fourfold change in $A_{590}$ show that it is unnecessary to adjust the inoculum $A_{590}$ value accurately to $0 \cdot 4$; isolates may therefore be assayed even if their growth is slow and/or does not reach high absorbances during inoculum growth.

\section{Isolation and screening of environmental isolates by Biolog assay with five classes of surfactant}

Environmental isolates were obtained by plating serial dilutions of epilithic bacteria on medium $M$ agar. Epilithic bacteria were obtained by resuspension of the biofilm on a flat stone taken from a site in a polluted South Wales river, using the method of Burton et al. (1982). The site chosen was directly beneath the outfall from a municipal sewage treatment plant. Such sites are known to be relatively rich in bacteria capable of biodegrading anionic surfactants (Anderson et al., 1988). Thirty isolates were selected at random and transferred to fresh medium $M$ plates for axenic growth.

Each isolate was inoculated from axenic plate culture separately into a $5 \mathrm{ml}$ aliquot of medium $\mathrm{M}$ containing a mixture of the surfactants $(0 \cdot 1 \mathrm{mM}$ each of SNS, Empicol ESB70, potassium undecan-2-yl sulphate, sodium 1dodecane sulphonate and NANSA HS80/S) in capped glass test-tubes $(125 \mathrm{~mm} \times 16 \mathrm{~mm})$. Isolates were incubated for $18 \mathrm{~h}$ at $30^{\circ} \mathrm{C}$ in a gyratory incubator at 150 r.p.m. Each isolate was harvested by centrifugation and washed three times with PBS and the final bacterial pellet resuspended in PBS to give an $A_{590}$ value in the range of $0 \cdot 1-0 \cdot 4$. The five known degraders were grown on medium $M$ supplemented with their respective surfactant and E. coli JM101 was grown on nutrient broth, all to mid-exponential phase and harvested according to this method.

The 36 isolates (i.e. 30 environmental isolates, 5 known degraders and E. coli JM101) were Biolog-assayed with each of the five classes of surfactants as shown in Table 2. Biolog colour was measured at $8 \mathrm{~h}$ intervals for a period of $64 \mathrm{~h}$ for the assays with PLAS, AES and SLAS, and at $12 \mathrm{~h}$ intervals for a period of $132 \mathrm{~h}$ for the assays with the more recalcitrant PANS and LABS. Preliminary experiments had shown that the maximum difference in Biolog

Fig. 4. Comparison of colour production in Biolog assay with growth on solid minimal medium containing $0.1 \%$ (w/v) surfactant for four classes of surfactant: PLAS, AES, SLAS and PANS. Bacterial growth (0, none; 1, poor; 2, good) was estimated after incubating the plates at $30^{\circ} \mathrm{C}$ for $7 \mathrm{~d}$. The known degrading organism for each surfactant is shown as a filled circle. 
colour between surfactant-degrading and non-degrading isolates occurred after $48 \mathrm{~h}$ for PLAS, AES and SLAS, after $108 \mathrm{~h}$ for PANS and after $132 \mathrm{~h}$ for LABS.

\section{Comparison of Biolog colour production with surfactant die-away}

Each of the 36 isolates was assayed for primary biodegradation of the same five classes of surfactant using smallscale die-away tests. A set of 37 die-away tubes containing $80 \mu \mathrm{M}$ SDS was inoculated $(5 \%, \mathrm{v} / \mathrm{v})$ individually with each of the 36 isolates, prepared according to the Biolog protocol. The 37th tube was inoculated with PBS to act as a sterile control. Four further sets of 37 die-away tubes were prepared, each set containing one of the four other surfactants used in the Biolog assay, and inoculated as for the SDS tubes. The die-away tubes were incubated at $30^{\circ} \mathrm{C}$ in a gyratory incubator at 150 r.p.m. The times for the known surfactant-degrading organisms to decrease the original concentration of the respective surfactant by approximately $95 \%$ had been determined previously (PLAS, $12 \mathrm{~h}$; AES, $12 \mathrm{~h}$; SLAS, $12 \mathrm{~h}$; PANS, $60 \mathrm{~h}$; LABS, $75 \mathrm{~h}$ ) and samples were taken from the corresponding sets of die-away tubes at these times and frozen at $-20^{\circ} \mathrm{C}$. All samples were assayed subsequently for MBAS, and the percentage loss of MBAS during the course of the die-away was calculated. These data have been compared with the corresponding production of Biolog colour in Fig. 3.

\section{Comparison of Biolog colour production with growth on surfactant}

Each of the 36 isolates previously Biolog-assayed with the five classes of surfactant was assayed for its ability to grow on each of these surfactants. Each isolate was inoculated on five agarose plates of minimal medium, each containing one of the five classes of surfactant at the concentration used previously to isolate the known degraders. The plates were incubated at $30^{\circ} \mathrm{C}$ for $7 \mathrm{~d}$ and bacterial growth was estimated visually and scored: 0 , no growth; 1 , poor growth; 2 , good growth. These data are compared with the Biolog assay data in Fig. 4. There are no data for LABS because, as discussed above, no single isolate was able to grow on this surfactant as sole carbon and energy source.

\section{DISCUSSION}

The majority of previous studies utilizing the Biolog methodology have involved measuring the Biolog well absorbances after a single, predetermined time, and little or no attention has been paid to the time dependency of colour development. Garland \& Mills (1991) investigated the appearance of Biolog colour with time and their results suggest that the kinetics of colour appearance give rise to a sigmoidal curve resembling the classic bacterial growth curve. Our results confirm this and we have shown that the appearance of Biolog colour with time may be adequately described by a modified logistic growth model. Parameter estimates from non-linear regression of experimental data fitted to this model proved useful in optimizing conditions for the Biolog assay.

Comparison of the results of Biolog assay with surfactant die-away tests for the 36 isolates (Fig. 3) showed that for each of the readily biodegradable surfactants (PLAS, AES and SLAS), three groups of organisms could be identified by visual inspection. First, large groups of organisms (25/36 for PLAS, 26/36 for AES and 31/36 for SLAS) are centred around the zero points of both axes (Biolog colour $<100$ for PLAS and $<50$ for AES and SLAS; die-away scores $<20 \%$ ); these groups are evidently comprised of non-surfactant-degrading organisms. Based on these data, Biolog thresholds for surfactant-degrading bacteria were set at 100 for PLAS, 50 for AES and 50 for SLAS. Members of a second, smaller group have low Biolog scores $(<100$ for PLAS and $<50$ for AES and SLAS), but show significant ( $>20 \%$ ) loss of MBAS activity. These organisms are primary degraders of surfactant but are not Biolog-positive. The third group shows loss of MBAS $(>20 \%)$ and high values of Biolog colour ( $>100$ for PLAS and $>50$ for AES and SLAS) : for PLAS, three of the environmental isolates and four of the known degrading organisms were in this group, while for AES there were three environmental isolates and three known degraders, and for SLAS, no environmental isolates and three known degraders. Since all the Biolog-positive isolates for these three surfactant classes showed high loss of MBAS during the surfactant die-aways, we conclude that all Biolog-positive organisms are primary surfactant-degrading organisms. However, the reverse is not true, and not all primary surfactantdegrading organisms are Biolog-positive. Previously, it has tacitly been assumed that organisms which accomplished primary biodegradation of alkyl sulphate esters by liberation of a long-chain alcohol, would also achieve ultimate biodegradation because the alcohol would be readily metabolized (White $\&$ Russell, 1994). Clearly this is not necessarily the case. None of the organisms which failed to accomplish primary degradation was found to be Biolog-positive. We believe this to be an important aspect of the validation process, because it demonstrates that the Biolog assay did not give any false-positive results.

The more recalcitrant surfactant classes (PANS and LABS) showed slightly different patterns (Fig. 3). Three groups were seen for PANS. The first was comprised of non-degraders (Biolog colour $<50$ and die-away scores $<10 \%)$. The second contained a single example, namely the LABS-degrading consortium, which showed high loss of MBAS but no Biolog colour. This shows that the consortium has good primary biodegradative activity towards PANS but shows no Biolog activity towards that surfactant. This is consistent with the observation that no member of the consortium was able to grow with PANS as sole carbon and energy source. The third group contained one organism which was both Biolog-positive and a primary surfactant degrader. This was the isolate obtained by enrichment culture on PANS. For LABS, only two groups were observed, namely the nondegrading organisms and the primary degrader/Biologpositive LABS-degrading consortium. As with the less 
recalcitrant surfactants, no false-positive results were seen with these more recalcitrant compounds.

Comparison of the Biolog assay with growth on surfactant (Fig. 4) showed that, with the exception of LABS, all Biolog-positive organisms were capable of growth on the corresponding surfactant as sole carbon and energy source, i.e. they were capable of ultimate biodegradation of the surfactant. The fact that no individual isolate was able to grow on NANSA HS80/S matches the observations of several authors including Jimenez et al. (1991), Sigoillot \& Nguyen (1992) and Terzic et al. (1992), all of whom found that a consortium was necessary to mineralize LABS. For the sulphated surfactants (PLAS, AES, SLAS), some organisms were capable of growth on surfactant as sole carbon and energy source but did not give Biolog-positive results. In view of the fact that the ability to grow on and mineralize surfactant should give rise to an increase in cell respiration and thus give a positive Biolog assay for that organism, the observation of such false-negatives is puzzling. The explanation may lie in the method used to grow the cells for the Biolog assay: although the growth medium $\mathrm{M}$ was supplemented with low concentrations of each surfactant $(0.5 \mathrm{mM}$ in total), this may have been insufficient to induce surfactantdegrading enzymes or to prevent the loss of plasmids which might encode for some degradative enzymes. Thus, the bacterial inoculum used in the Biolog assay may have been incapable of biodegrading the surfactant at a sufficient rate to give a positive Biolog result. In comparison, when the bacteria are inoculated in a medium containing the surfactant as the sole carbon and energy source, the ability to biodegrade the surfactant is necessarily maintained. To overcome this problem, each isolate would need to be grown individually on each surfactant, as indeed was done in this study with the known surfactant-degrading organisms. This should prevent loss of biodegradative capacity but would increase the workload of the assay by a factor of five. When dealing with large numbers of environmental isolates, such an increase in the time required is unhelpful. Moreover, in natural aquatic systems alternative carbon sources are likely to accompany surfactants. Consequently the Biolog protocol in which cells grow in the combined presence of surfactant and other carbon sources, is likely to reflect more closely the numbers of degraders that are active in the environment.

The adaptation and development of the Biolog assay has facilitated investigation of the pattern of anionic surfactant biodegradation in 30 environmental bacterial isolates from a polluted riverine site. That fraction of the epilithic isolates which gave a positive reaction in the Biolog assay was about $10 \%$ for PLAS and AES, and zero for SLAS, PANS and LABS. The value for PLAS is in close agreement with previous studies of polluted rivers in South Wales (Anderson et al., 1988; White et al., 1985). The absence of any SLAS Biolog-positive isolates was surprising, particularly since five isolates were capable of growth on SLAS and thus were Biolog false-negatives. This aside, the fractions of degrading organisms appears to reflect the established order of recalcitrance of these surfactant classes (Swisher, 1987). Thus, sulphate esters were generally the most readily degradable and had the highest fraction of Biolog-positive isolates, while the sulphonates were more recalcitrant and had the lowest fraction of Biolog-positive results. The SDS-degrading isolate, Pseudomonas C12B, gave positive results for all the classes of sulphated surfactants, a versatility which matches the known battery of sulphatase activity in this organism (Bartholomew et al., 1978; Cloves et al., 1980; Shaw et al., 1980; Bateman et al., 1986; Hales et al., 1986). The LABS-degrading consortium appears to be metabolically diverse and is capable of biodegrading all the sulphated and sulphonated surfactants used during this study.

The basic Biolog methodology as modified in this study to investigate anionic surfactant biodegradation, has many other potential applications. For example, it can be used to investigate the biodegradation specificities of pure isolates towards homologous series of compounds. It can also be used to assay whole environmental samples such as those obtained from resuspended biofilms. The use of the LABS-degrading consortia in this study and the use of environmental samples by Garland \& Mills (1991) demonstrates that the Biolog assay can be used to test not only pure isolates but also whole bacterial communities. The direct testing of such intact communities without an intermediate growth step in the laboratory (which introduces an artificial selection) will help provide further insight into the microbial ecology of natural environments.

Little research utilizing the Biolog MT plate has been published, and the manufacturer's bibliography, dated May 1994, contains a total of six such papers. Previous research utilizing this methodology has studied the biodegradation of a variety of organic compounds (vide infra); those researchers concentrated on the results obtained using Biolog and did not report any validation of the method against more traditional methods. In contrast, the work presented here addresses this problem with respect to the use of Biolog MT plates with anionic surfactants and proves that it is a valuable tool in investigating the ecology, microbiology and biochemistry of surfactant biodegradation.

\section{ACKNOWLEDGEMENTS}

We wish to thank Albright and Wilson for their donations of surfactant samples and Dr M. J. E. Hewlins for NMR analysis of surfactant samples. This research was supported by a Natural Environment Research Council grant (GR3/7858).

\section{REFERENCES}

Anderson, D. J., Day, M. J., Russell, N. J. \& White, G. F. (1988). Temporal and geographical distributions of epilithic sodium dodecyl sulfate-degrading bacteria in a polluted South Wales river. Appl Environ Microbiol 54, 555-560.

Anderson, D. J., Day, M. J., Russell, N. J. \& White, G. F. (1990). Die-away kinetic analysis of the capacity of epilithic and planktonic bacteria from clean and polluted river water to biodegrade sodium dodecyl sulfate. Appl Environ Microbiol 56, 758-763. 
Bartholomew, B., Dodgson, K. S. \& Gorham, S. G. (1978). Purification and properties of the S1 secondary alkylsulphohydrolase of the detergent-degrading micro-organism Pseudomonas C12B. Biochem J 169, 659-667.

Bateman, T. J., Dodgson, K. S. \& White, G. F. (1986). Primary alkylsulphatase activities of the detergent-degrading bacterium Pseudomonas C12B. Biochem J 236, 401-408.

Biolog Inc. (1993). MT MicroPlate; Instructions for Use. Hayward, CA : Biolog Inc.

Bochner, B. R. (1989a). 'Breathprints' at the microbial level. ASM News 55, 536-539.

Bochner, B. R. (1989b). Sleuthing out bacterial identities. Nature 339, 157-158.

Bochner, B. R. \& Savageau, M. A. (1977). Generalized indicator plate for genetic, metabolic, and taxonomic studies with microorganisms. Appl Environ Microbiol 33, 434-444.

Burton, N. F., Day, M. J. \& Bull, A. T. (1982). Distribution of bacterial plasmids in clean and polluted sites in a South Wales river. Appl Environ Microbiol 44, 1026-1029.

Cloves, J. M., Dodgson, K. S., White, G. F. \& Fitzgerald, J. W. (1980). Purification and properties of the P2 primary alkylsulphohydrolase of the detergent-degrading bacterium Pseudomonas C12B. Biocbem J 185, 23-31.

Garland, J. L. \& Mills, A. L. (1991). Classification and characterization of heterotrophic microbial communities on the basis of patterns of community-level sole-carbon-source utilization. Appl Environ Microbiol 57, 2351-2359.

Gordon, R. W., Hazen, T. C. \& Fliermans, C. B. (1993). Rapid screening for bacteria capable of degrading toxic organic compounds. J Microbiol Methods 18, 339-347.

Hales, S. G., Watson, G. K., Dodgson, K. S. \& White, G. F. (1986). A comparative study of the biodegradation of the surfactant sodium dodecyltriethoxy sulphate by four detergent-degrading bacteria. J Gen Microbiol 132, 953-961.

Hauthal, H. G. (1992). Trends in surfactants. Chim Oggi 10, 9-13.

Hayashi, K. (1975). A rapid determination of sodium dodecyl sulfate with Methylene Blue. Anal Biochem 67, 503-506.

Jimenez, L., Breen, A., Thomas, N., Federle, T. W. \& Sayler, G. S. (1991). Mineralization of linear alkylbenzene sulfonate by a fourmembered aerobic bacterial consortium. Appl Environ Microbiol 57, 1566-1569.

Jones, J. G. (1970). Studies on freshwater bacteria. Effect of medium composition and method on estimates of bacterial population. $J$ Appl Bacteriol 33, 679-686.

Jones, D., Pell, P. A. \& Sneath, P. H. A. (1991). Maintenance of bacteria on glass beads at $-60^{\circ} \mathrm{C}$ to $-76^{\circ} \mathrm{C}$. In Maintenance of Microorganisms and Cultured Cells. A Manual of Laboratory Methods, pp. 31-45. Edited by B. E. Kirksop \& A. Doyle. London: Academic Press.

Lee, B. D., Lehman, R. M. \& Colwell, F. S. (1992). Screening of microbes from deep-subsurface environments for the ability to degrade nonvolatile organic contaminants. Abstracts of the 92nd Meeting of the American Society for Microbiology, p. 384.

Odocha, I., Wang, S., Horacek, I., Wong, S., Kresta, I. \& Graves, J. (1994). Biodegradability assessment of isocyanate based polymers. Abstracts of the 94th General Meeting of the American Society for Microbiology, p. 463.

Payne, W. J. \& Feisal, V. E. (1963). Bacterial utilization of dodecyl sulfate and dodecylbenzene sulfonate. Appl Microbiol 11, 339-344.

Shaw, D. J., Dodgson, K. S. \& White, G. F. (1980). Substrate specificity and other properties of the inducible $\mathrm{S} 3$ secondary alkylsulphohydrolase purified from the detergent-degrading bacterium Pseudomonas C12B. Biochem J 187, 181-190.

Sigoillot, J. C. \& Nguyen, M. H. (1992). Complete oxidation of linear alkylbenzene sulfonate by bacterial communities selected from coastal seawater. Appl Environ Microbiol 58, 1308-1312.

Strong-Gunderson, J. M., Palumbo, A. V. \& Scarborough, A. O. (1992). New method for rapidly determining microbial utilization of volatile contaminants. Abstracts of the 92nd Meeting of the American Society of Microbiology, p. 371.

Swisher, R. D. (1987). Surfactant Biodegradation. New York: Marcel Dekker.

Terzic, S., Hrsak, D. \& Ahel, M. (1992). Enrichment and isolation of linear alkylbenzenesulphonate (LAS) degrading bacteria from estuarine and coastal waters. Mar Pollut Bull 24, 199-204.

Thomas, O. R. T. (1987). Development of solid support systems for the degradation of surfactants. PhD Thesis, University of Wales.

Victorio, L., Allen, D. G., Gilbride, K. A. \& Liss, S. N. (1993a). Biodegradation profiles of microbial communities in wastewater treatment systems. Abstracts of the Joint Annual Meeting of the Society for Industrial Microbiology and the Canadian Society of Microbiologists, p. 70 .

Victorio, L., Allen, D. G. \& Liss, S. N. (1993b). Phenotypic fingerprinting of biologically-based wastewater treatment. Abstracts of the 92nd Meeting of the American Society for Microbiology, p. 425.

White, G. F. \& Russell, N. J. (1994). Biodegradation of anionic surfactants and related molecules. In Biochemistry of Microbial Degradation, pp. 143-177. Edited by C. Ratledge. Dordrecht: Kluwer Academic Publishers.

White, G. F., Lillis, V. \& Shaw, D. J. (1980). An improved procedure for the preparation of alkyl sulphate esters suitable for the study of secondary alkylsulphohydrolase enzymes. Biochem J 187, 191-196.

White, G. F., Russell, N. J. \& Day, M. J. (1985). A survey of sodium dodecyl sulphate (SDS) resistance and alkylsulphatase production in bacteria from clean and polluted river sites. Environ Pollut (Series A) 37, 1-11.

Zwietering, M. H., Jongenburger, F. M., Rombouts, F. M. \& van 'T Riet, K. (1990). Modelling of the bacterial growth curve. Appl Environ Microbiol 56, 1875-1881.

Received 27 February 1995; revised 2 June 1995; accepted 13 July 1995. 